\title{
Detection of Femtomole and Sub-femtomole Levels of Peptides by Tandem Magnetic Sector/Reflectron Time-of-Flight Mass Spectrometry and Matrix-Assisted Laser Desorption Ionization
}

\author{
F. H. Strobel, T. Solouki, M. A. White, and D. H. Russell \\ Department of Chemistry, Texas A\&M University, College Station, Texas, USA
}

\begin{abstract}
This article describes results of low-level (sub-femtomole) detection of peptides by matrixassisted laser desorption ionization. The matrix-assisted laser desorption ionization method can be used for low-level detection of the parent ion, either $[\mathrm{M}+\mathrm{H}]^{+}$or $[\mathrm{M}+\mathrm{Na}]^{+}$, and collision-induced dissociation of the parent ion can be performed at the picomole level. The instrument used for these studies is a novel high-performance magnetic sector (electric(E)/magnetic(B) sector)/reflectron time-of-flight (TOF) tandem mass spectrometer (EB/TOF). (J Am Soc Mass Spectrom 1991, 2, 91-94)
\end{abstract}

$\mathrm{D}$ evelopment of mass spectrometric methods for the analysis of polar, thermally labile compounds at the picomole to femtomole level is now a realistic objective [1]. Although molecular weight determination is a primary objective for mass spectrometric analysis, complete or partial sequence information on peptides (up to ca 2000-2500 da) can be obtained by combining collision-induced dissociation (CID) with fast atom or $\mathrm{Cs}^{+}$ion bombardment of a liquid matrix containing the sample [2]. Because the yield of intact molecular ions (typically $[\mathrm{M}+\mathrm{H}]^{+}$) is high, matrix-assisted laser desorption [3] could potentially impact structural mass spectrometry, but such experiments are limited by current instrument technology. For example, tandem mass spectrometry is not a routine experiment for time-of-flight $[4]$ or other pulsed instruments, and pulsed ionization methods are not generally compatible with conventional analytical tandem mass spectrometers (magnetic sector or quadrupole instruments) [5]. In terms of the mass resolution required for selection of the analyte ion by MSI, high-performance magnetic sector instruments are advantageous for studies of complex biomolecules. This article describes the first results from matrix-assisted laser desorption/tandem mass spectrometry experiments. The experiment is performed by using a high-performance magnetic sector (EB configuration) as MSI and a reflectron time-of-flight (TOF) as MSII.

The general features of the EB/TOF instrument

Address reprint requiests to David $H$. Russell, Department of Chemistry, Texas A \& M University, College Station, TX 77843. have been described previously [6]. Ions formed in the ion source are accelerated to $8 \mathrm{keV}$, and the analyte ion $\left(\mathbf{m}_{1}^{+}\right)$is mass-selected by MSI (Kratos MS-50) [6]. Prior to entering the collision cell, $\mathrm{m}_{1}^{+}$is

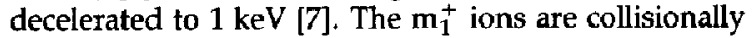
activated ( $\mathrm{He}, \mathrm{Ar}$, or $\mathrm{Xe}$ target gas), and the $\mathrm{CID}$ product ions $\left(\mathrm{m}_{\mathrm{i}}^{+}\right)$are then reaccelerated to $8 \mathrm{keV}$ and mass analyzed by the reflectron TOF. ${ }^{1}$ The TOF data are acquired by using a LeCroy 4208 time-to-digital converter (LeCroy Corp., Chestnut Ridge, NY). The time-domain data are stored by the computer (IBM $286 \mathrm{PC} / \mathrm{AT}$ ), and data from successive laser shots are stored and signal-averaged. Typically, data from 1000 to 10,000 laser shots (repetition rate ca $3 \mathrm{~Hz}$ ) are accumulated.

The matrix-assisted laser desorption iunication is performed by dissolving a measured amount of sample in o-nitrobenzyl alcohol (NBA) to yield a solution that is $1 \mu \mathrm{g} / \mu \mathrm{L}$. The standard peptide/NBA solution is then diluted to the desired level and a $1-\mu \mathrm{L}$ aliquot of solution is placed directly onto the direct insertion probe. The probe is then inserted into the ion source vacuum chamber where it is exposed to the laser irradiation (a 10-ns laser pulse (353 nm) at a laser power density of ca $10^{5}$ watts $\mathrm{cm}^{-2}$; Questek Series 2000 exciner (Questek, Inc, Billerica, MA) using $X e / F_{2}$ gas mixture). The yield for $[\mathrm{M}+\mathrm{H}]^{+}$and $[\mathrm{M}+\mathrm{Na}]^{+}$

\footnotetext{
${ }^{1}$ Details of the apparatus will be published at a future date; preliminary results from the $\mathrm{EB} / \mathrm{TOF}$ were presented at a recent meeting, see F. Strobel and D. H. Russell, Annual Conference on Mass Spectrometry and Allied Topics, Tucson, Arizona, June 3-8, 1990, paper FOA $10: 40$.
} 

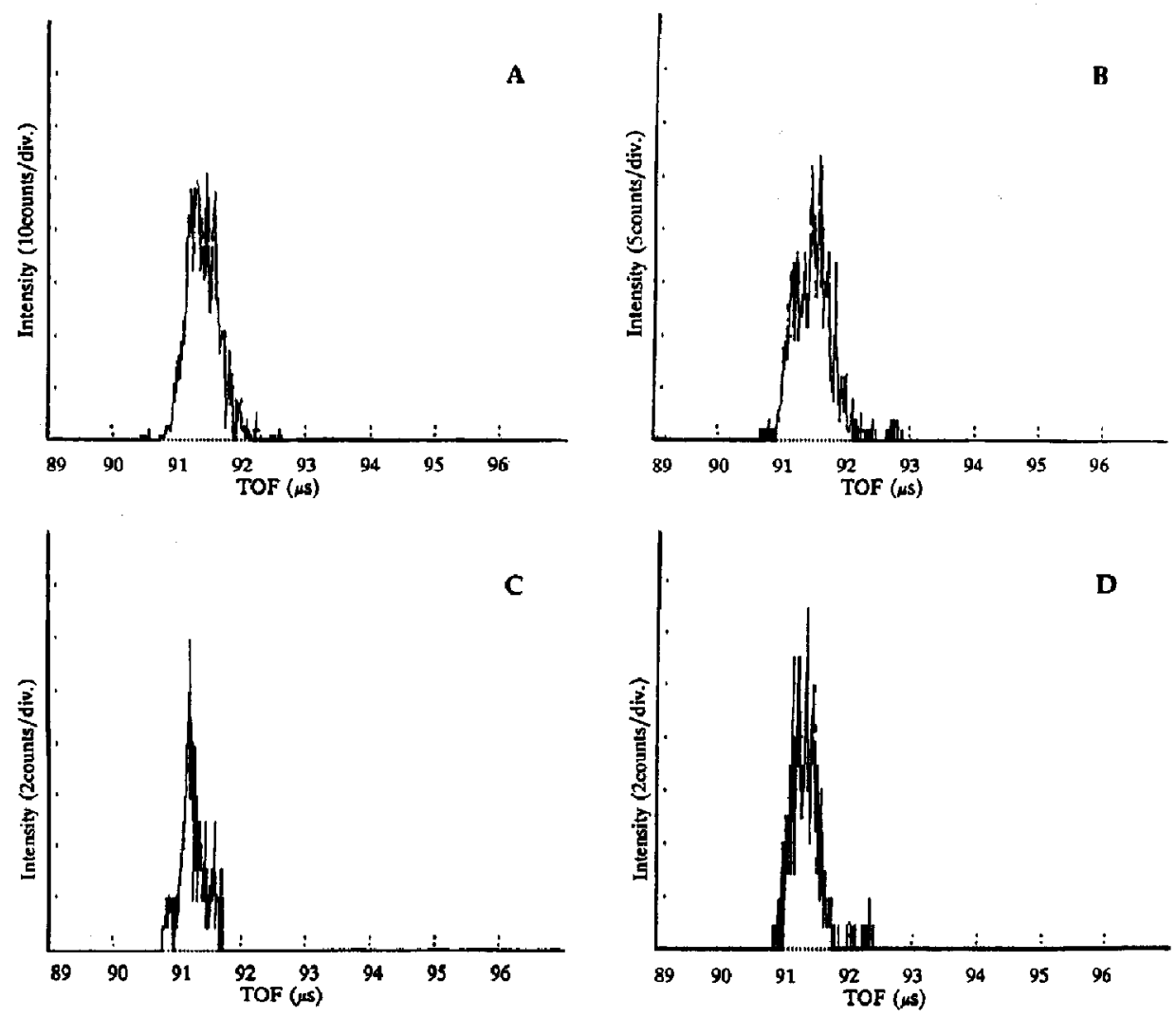

Figure 1. Arrival time distribution data for the $[\mathrm{M}+\mathrm{H}]^{+}$ion of angiotensin II formed by matrix-assisted pulsed-UV (353 nm)-laser desorption ionization. Sample size is (a) 10 picomol (b) 100 femtomole, (c) 1 femtomole, and (d) 0.1 femtomole.

ions can be enhanced by addition of a small amount (parts per thousand) of sinapic acid (3,5-dimethoxy-4hydroxycinnamic acid) or by increasing the laser flux density. Although matrix-assisted laser desorption ionization can be performed from a solid-matrix (e.g., sample plus sinapic acid), we find the ion yield to be much more stable and of longer duration from the liquid matrix.

Figure 1 contains the arrival time distribution data for the $[\mathrm{M}+\mathrm{H}]^{+}$ion $(m / z$ 1046) of angiotensin II. The time axis corresponds to the total flight time of the ion from the ion source to the microchannel plate detector of the TOF. The start time, $t_{\alpha}$ is defined by a TTL pulse (jitter $+/-0.5 \mathrm{~ns}$ ) from the control computer (IBM PC/AT). The actual time axis displayed in Figure 1 corresponds to an 8.3- $\mu$ s time window centered about the flight time $(91.3 \mu \mathrm{s})$ for $\mathrm{m} / \mathrm{z} 1046$. Figure 1a is the arrival time distribution data obtained for a 10-picomole sample. (Ten picomole is the actual amount of sample placed onto the probe.) Figure $1 b-d$ contains the same data for sample sizes of 100 femtomole, 1 femtomole, and 0.1 femtomole, respectively. The background spectrum was checked in two ways: (1) The ion count rate with MSI static at $\mathrm{m} / \mathrm{z}$
1046 was measured with a blank, for example, NBA matrix with sinapic acid loaded onto the probe without sample. This control gave a zero count signal for 1000 laser shots. (2) With NBA, sinapic acid, and angiotensin II loaded onto the probe, the mass-tocharge region between 1000 and 1100 was examined by manually scanning the magnet; no ion signals greater than $0.01 \%$ of the $[\mathrm{M}+\mathrm{H}]^{+}$ion were observed in this region except for the $[\mathrm{M}+\mathrm{Na}]^{+}(\mathrm{m} / \mathrm{z}$ $1068)$ and $[\mathrm{M}+\mathrm{K}]^{+}(m / z 1084)$ ions. These data illustrate several important points: (1) matrix-assisted pulsed-UV-laser desorption ionization is compatible with a magnetic sector tandem instrument for detection of the $[\mathrm{M}+\mathrm{H}]^{+}$(as well as $[\mathrm{M}+\mathrm{Na}]^{+}$or $[\mathrm{M}+$ $\mathrm{K}^{+}$) ion; (2) the sensitivity of matrix-assisted laser desorption exceeds that of liquid secondary ion mass spectrometry by ca $10^{2}$ to $10^{3}$; (3) the EB/TOF concept is advantageous over other methods for isolating $\mathrm{m}_{1}^{+}$ because the noise and background signals are eliminated by instrument filtering [8]. We anticipate that detection levels can be pushed even lower by rather simple improvements to the apparatus, especially by improving the extraction optics of the ion source, optimization of sample handling methods, and fur- 


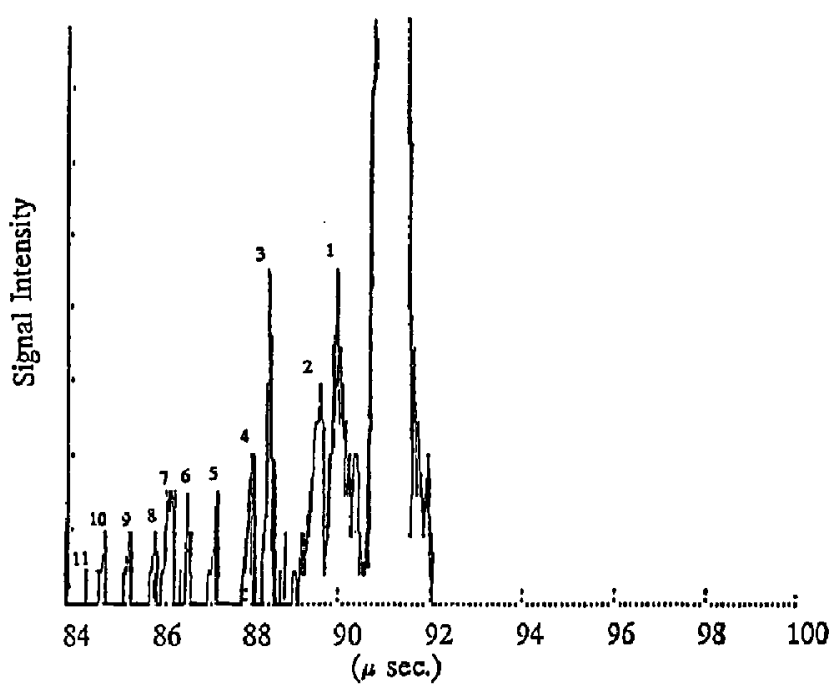

Figure 2. $\mathrm{EB} / \mathrm{TOF} \mathrm{CID}$ spectrum for the $[\mathrm{M}+\mathrm{H}]^{+}$ion ( $m / z$ 1046) of angiotensin II (10 picomoles); He target gas and 1-keV collision energy. ther development/understanding of the photophysics of matrix-assisted laser desorption ionization. ${ }^{2}$

Figure 2 contains a portion $(m / z 300-1075)$ of the EB/TOF CID spectrum of angiotensin II. This spectrum was obtained by signal averaging the data from 1000 laser shots. The collision gas (helium) pressure corresponds to $50 \%$ attenuation of normal ion beam, and the collision energy was $1000 \mathrm{eV}$. Although each of the CID product ions can be assigned (see Table I), the CID spectrum differs significantly from previously reported data [9]. For example, an important ion in the CID spectrum ( $m / z 629$; peak 5 ) is formed by a combination of an $A_{8}$ and $Y_{5}$ bond cleavage process, denoted by $A_{8} / Y_{5}$ [10]. In addition, the fragment ions at $m / z$ 907, $m / z 866, m / z 742$, and $m / z 707$ (peaks 1 to 4 , respectively) arise by consecutive reactions involving cleavage of the peptide backbone and luss of a side-chain. We think that the higher relative abundance of the product ions involving consecutive reactions is due to the larger acceptance angle for fragment ions formed by close-impact (large scattering angle) collisions [11]. However, there may be signifcant differences in the CID spectra of ions formed by laser desorption vis-à-vis ions formed by liquid secondary ion mass spectrometry. Further studies of the CID spectra of laser desorbed ions are underway.

\footnotetext{
${ }^{2} \mathrm{~A}$ major difficulty encountered with low femtomole and attomole detection is sample "carry over" by the probe from one sample loading to the next. For example, if a solution containing 100 femtomole of peptide is placed on the probe tip, allowed to stand for 10 min then rinsed with acetone, and a clean portion of NBA is added to the probe and inserted into the mass spectrometer, ample ion signal is obtained on laser irradiation. To ensure that such effects were not complicating the current experiments, proper cleaning procedures were used to determine that the signals did not arise by sample "carry over." The cleaning procedures involved three acetone washes, laser "cleaning" of the probe, and neat NBA loadings analysis to determine the level of background signal. In all cases reported (in Figure 1) the level of background signal was less than $0.1 \%$ that for the sample.
}

We wish to call attention to two additional aspects of the CID data: (1) the number of ions detected in the EB/TOF experiment and (2) the mass resolution of the reflectron TOF. The CID spectrum is relatively free of background ions because the large background typically encountered in TOF experiments is eliminated by MS-I. The large dynamic range of the experiment can be illustrated by close examination of peaks 8 through 11. Although the signals are of very low abundance, corresponding to a total of 10 counts, the peaks are reproducible to $+/-10-20 \%$, which is typical for low-level signals encountered in other tandem mass spectrometry experiments. Note that peak 11 is comprised of a single count and can be used to estimate the background count level. The second point deals with the widths of the CID peaks. Although the arrival time distribution of the $[\mathrm{M}+\mathrm{H}]^{+}$ion is approximately $1 \mu \mathrm{s}$, the widths of some of the CID

Table 1. EB/TOF collision-induced dissociation data for the $[\mathrm{M}+\mathrm{H}]^{+}$ion $(m / z$ 1046) of angiotensin II formed by matrix-assisted pulsed-UV ( $353 \mathrm{~nm})$-laser desorption

\begin{tabular}{cccc}
\hline Peak \# & $\begin{array}{c}\text { Measured } \\
(\mathrm{m} / \mathrm{z})\end{array}$ & $\begin{array}{c}\text { Calculated } \\
(\mathrm{m} / \mathrm{z})\end{array}$ & Identity \\
\hline \hline 1 & 907 & 909 & $\mathrm{~A}_{8}-\mathrm{C}_{7} \mathrm{H}_{7}$ \\
2 & 866 & 866 & $\mathrm{X}_{7}-\mathrm{C}_{7} \mathrm{H}_{7}$ \\
3 & 742 & 741 & $Z_{6}-\mathrm{OH}$ \\
4 & 707 & 710 & $\mathrm{X}_{6}-\mathrm{C}_{7} \mathrm{H}_{7}$ \\
5 & 629 & 629 & $\mathrm{~A}_{8} / \mathrm{Y}_{5}$ \\
6 & 571 & 574 & $\mathrm{C}_{5} / \mathrm{X}_{7}$ \\
7 & 537 & 538 & $\mathrm{~B}_{7} / \mathrm{X}_{5}$ \\
8 & 507 & 510 & $\mathrm{C}_{7} / \mathrm{Z}_{5}$ \\
& & 510 & $\mathrm{~B}_{7} / \mathrm{Y}_{5}$ \\
9 & & 510 & $\mathrm{~A}_{7} / \mathrm{X}_{5}$ \\
10 & 461 & 461 & $\mathrm{C}_{4} / \mathrm{X}_{7}$ \\
11 & 417 & - & $\mathrm{N} / \mathrm{A}$ \\
\hline
\end{tabular}

$N / A=$ not assigned. 
peaks are significantly less, for example, $100 \mathrm{~ns}$. One reason is the low ion statistics, which lead to sharper peaks than when hundreds of ions are detected, A second reason is that the width of the $[\mathrm{M}+\mathrm{H}]^{+}$ion signal and the CID production signals are dependent upon the tuning of the deceleration lens and the reflectron TOF. No attempt has been made to optimize (in terms of resolution) the TOF tuning for the data displayed in Figure 2 [12].

The mass resolution of the EB/TOF spectrum is limited by the arrival time distribution (ca $1 \mu \mathrm{s}$ ) of the $[\mathrm{M}+\mathrm{H}]^{+}$ion (a limitation imposed by the extraction optics of the ion source), and the sensitivity of the EB/TOF CID experiment is limited by the collection efficiency of the reflectron TOF analyzer [13]. These limitations are not inherent to the experiment and steps to correct/improve the data are currently underway. In spite of the limitations, the present results clearly illustrate the potential for performing structural characterization of biomolecules by combining novel instrumentation with matrix-assisted pulsedUV-laser desorption ionization. Although analysis/ structural characterization at the attomole level is complicated due to difficulties associated witth sample handling and may not be a practical objective for the analysis of unknown peptides, the current results illustrate the ultrahigh sensitivity that can be obtained by combining these methods.

\section{Acknowledgment}

This research is supported by the Department of Energy, Division of Chemical Sciences, Office of Basic Energy Sciences (FG05-85ER13434) and the Department of Energy, Division of
University and Industry Programs, 1989 University Research Instrumentation Program (DE-FG05-89ER75502).

\section{References}

1. See, for example, Burlingame, A. L.; Millington, D. S.; Norwood, D. L.; Russell, D. H. Anal. Chem. 1990, 62, 268 R.

2. (a) Tomer, K. B.; Crow, F. W.; Gross, M. L. Int. J. Mass Spectrom. Ion Proc. 1983, 46, 375; (b) Crow, F. W.; Tomer, K. B.; Looker, J. H.; Gross, M. L. Anal. Biochem. 1986, 155, 286; (c) Amster, I. J.; Baldwin, M. A.; Cheng, M. T.; Proctor, C. J.; McLafferty, F. W. J. Am. Chem. Soc. 1983, 105, 1654; (d) Tomer, K. B. Mass Spectrom Rev. 1989, 8, 445.

3. (a) Karas, M.; Hillenkamp, F. Anal. Chem. 1988, 60, 2301; (b) Beavis, R. C.; Chait, B. T. Rapid Commun. Mass Spectrom. $1989,3,436$.

4. Schueler, B.; Beavis, R.; Ens, W.; Main, D. E.; Tang, X.; Standing, K. G. Int. J. Mass Spectrom. Ion Proc. 1989, 92, 185.

5. Tecklenburg, R. E., Jr.; Castro, M. E.; Russell, D. H. Anal. Chem. 1989, 61, 153.

6. Tecklenburg, R. E., Jr.; Russell, D. H. Mass Spectrom. Rev. $1990,9,405$.

7. Tecklenburg, R. E.; Jr.; Sellers-Hann, L.; Russell, D. H. Int. J. Mass Spectrom. lon Proc. 1989, 87, 111.

8. Cooks, R. G.; Busch, K. J. Chem. Ed. 1982, 59, 926.

9. Konig, W. A.; Aydin, M.; Schulze, U.; Rapp, U.; Hohn, M.; Pesch, R.; Kalikhevitch, V. N. Int. J. Mass Spectrom. Ion Proc. 1983, 46, 403.

10. Russell, D. H.; McGlohon, E, S.; Mallis, L. M. Anal. Chem. $1988,60,1818$.

11. Strobel, F.; Russell, D. H.; Futrell, J. H. Manuscript in preparation.

12. Tang, $X$;; Ens, W.; Mayer, F.; Standing, K. G.; Westmore, J. B. Rapid Commun. Mass Spectrom. 1989, 3, 443.

13. Sichey, K. L.; Cooks, R. G.; Kraft, A.; Grix, R.; Wollinik, H. Int. J. Mass Spectrom. Ion Proc. 1990, 94, 1. 